\title{
Histórico da Ortodontia Paulista
}

\author{
Dr. Décio Rodrigues Martins \\ Professor Titular da Disciplina de Ortodontia da Faculdade \\ de Odontologia de Bauru - Universidade de São Paulo
}

Como relatamos no artigo anterior (nov/dez. 2003) o Prof. Arthur do Prado Dantas, no decorrer dos anos 50, selecionou jovens promissores e com vocação para a docência, para o devido treinamento e aprendizagem da teoria e da prática das Ortodontias Preventiva e Corretiva. Integravam a $1^{\text {a }}$ turma de estagiários os Drs. Sebastião Interlandi, Manoel Carlos Muller de Araújo, Jorge Gonçalves Dias, Jairo Corrêa, Reynaldo Baracchini, todos da capital e o Dr. Décio Rodrigues Martins de Lins, no interior de S.Paulo.

Com a criação das Faculdades já mencionadas e antevendo a necessidade de docentes capacitados, preparou-os para assumirem as respectivas disciplinas naqueles estabelecimentos de ensino.

Após alguns anos como estagiários, o Dr. Sebastião Interlandi foi contratado em 1957 e o Dr. M. C. Müller de Araújo em 1958, como Professores Assistentes da Cadeira de Ortodontia e Odontopediatria, da Faculdade de Odontologia da USP, que naquela época constituíam uma só disciplina.

E a esperada demanda logo se apresentou; as novas Faculdades necessitavam de professores e o único manancial de formação ortodôntica era o insigne Mestre, Dr. Dantas, que prontamente o espargiu por todo o Estado. Em 1956, o Dr. Décio R. Martins assumiu a cadeira de Ortodontia da Faculdade de Odontologia de Lins (Metodista); em 1959, o Dr. Jorge Gonçalves Dias foi contratado pela Faculdade de Odontologia de Araraquara, que havia sido encampada pela Unesp, em 1957 e o Dr. M. C. Müller de Araújo em 1960, na Faculdade de Odontologia de Piracicaba.

Assim, ao despontar o ano de 1960 quase todos da $1^{a}$ turma selecionada pelo Dr. Dantas já haviam assumido o mister para o qual foram preparados.

Os remanescentes Drs. Jairo Correa e Reynaldo Baracchini incumbiram-se de dinamizar a especialidade no Serviço Dentário Escolar, instruindo os colegas para exercerem as Ortodontias preventiva e interceptora junto aos jovens dos estabelecimentos escolares.

Tanto aqueles profissionais que haviam realizado especializações no exterior, como os que freqüentaram os cursos de Ortodontia oferecidos pelo Dr. Dantas na Associação Paulista de Cirurgiões Dentistas (APCD), de 1951 a 1955, que agora militavam na clínica, sentiram a necessidade de se arregimentarem, não só para tratar de assuntos pertinentes à especialidade, como para um aperfeiçoamento científico. Para tanto, criaram uma Secção de Ortodontia na APCD onde realizavam suas reuniões e conferências.

E em 1957, sentindo a necessidade de ampliar seus conhecimentos e confabular com colegas estrangeiros, promoveram o $1^{\circ}$ evento no gênero realizado no país, a $1^{\text {a }}$ Semana Paulista de Ortodontia, na sede da APCD.

Como Presidentes de honra, pontificavam Dr. Edmundo Nejm, Presidente da União Odontológica Brasileira (atual ABO), Dr. Alfredo Reis Viegas, Presidente da APCD e o Dr. Arthur do Prado Dantas, Professor da Faculdade de Farmácia e Odontologia da USP e iniciador do ensino de Ortodontia no Estado de S. Paulo.

Como organizadores do evento figuravam os Drs. Paulo Affonso de Freitas, como Presidente, Manoel Carlos Müller de Araújo, como Secretário e Nelson Junqueira de Andrade, como Tesoureiro.

Para ministradores de Cursos, foram convidados os Drs. Raul Otaño Antier, Fernando Archain e José Mayoral, ilustres colegas da Argentina, que indiscutivelmente, na época encontravam-se sobremaneira avançados na nobre especialidade de Angle (Fig. 1). Como conferencistas, entre outros destacaram-se os conterrâneos Drs. Arthur do Prado Dantas, de S.Paulo e José Édimo Soares Martins, Hélio de O. Fernandes e Carlos de Souza Telles, do Rio de Janeiro. O discurso de encerramento foi realizado pelo Dr. Ademar R. Terra, do Rio Grande do Sul, que vaticinou, com sabedoria, que este seria o primeiro passo de uma grande caminhada, rumo à excelência da Ortodontia, como de fato ocorreu. 


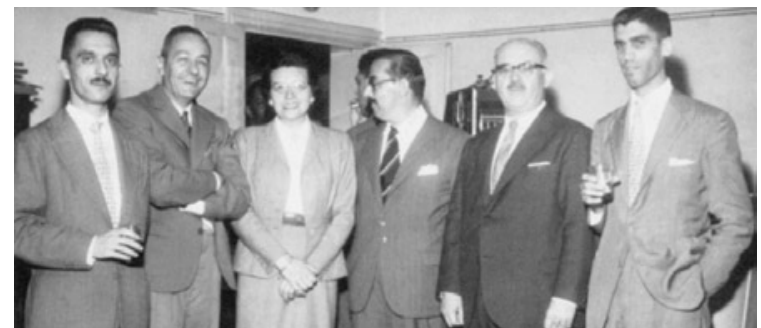

FIGURA 1 - Da esquerda para a direita Dr. M. C. Müller de Araújo, Dr. Raúl Otaño Antier, Dona Pilar Ostivar, Dr. Fernando Archain, Dr. José Mayoral e Dr. Paulo Affonso de Freitas, respectivamente, secretário, participantes e Presidente da $1^{\text {a }}$ Semana Paulista de Ortodontia.

E no início de 1960, os mesmos idealistas partiram para uma empreitada decisiva para a Ortodontia, a criação de uma Associação que não só congregasse a especialidade, como também difundisse seus conhecimentos, realizando Encontros, Semanas e Congressos Ortodônticos. Fundaram então a Sociedade Paulista de Ortodontia (SPO).

A $1^{\text {a }}$ Diretoria constou dos seguintes colegas Doutores:

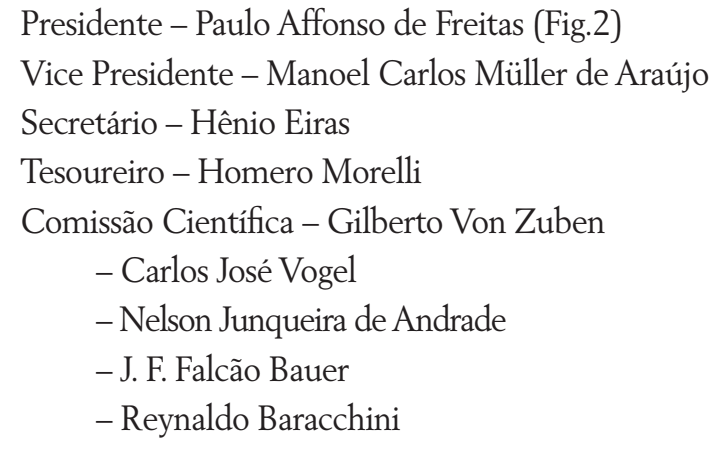

Está Diretoria regeu os destinos da SPO de 1960 a 1964, tendo como sede provisória os próprios da APCD.

Os ortodontistas já contavam então com uma Associação atuante, mas outros entraves precisavam ser vencidos. E um que afligia não só os neófitos, mas a categoria toda, era a aquisição dos materiais ortodônticos, pois não havendo quem os fornecesse, somente podiam ser adquiridos no exterior.

Felizmente, nos meados dos anos 50, uma assistente odontológica argentina, Dna. Pilar Ostivar (Fig.1) ao ditar um curso para Auxiliares de Odontologia na Escola de Aperfeiçoamento da APCD, percebeu essa lacuna e

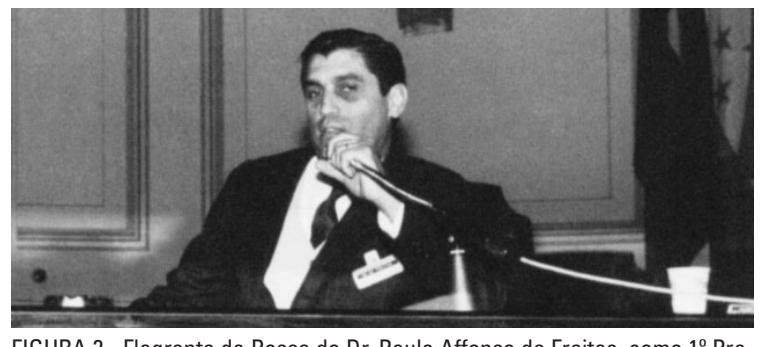

FIGURA 2 - Flagrante da Posse do Dr. Paulo Affonso de Freitas, como $1^{\circ}$ Presidente da Sociedade Paulista de Ortodontia (SPO).

resolveu se instalar no Brasil criando a empresa "Brasil Orthodontic", organização pioneira no país, a serviço da Ortodontia Brasileira. Representando as firmas Unitek e Orthoband (americanas), além de outras argentinas, facilitou deveras, o crescimento da prática ortodôntica de então, inclusive com a fundação de uma fábrica de bandas ortodônticas. Indiscutivelmente, nós os pioneiros somos muito gratos a essa gentil Senhora pelo muito que nos auxiliou nesse mister.

Indubitavelmente, os anos 60 foram decisivos para o alavancamento e o aprimoramento da nossa especialidade, pois os jovens recém - admitidos logo perceberam a necessidade premente de um tirocínio ortodôntico que os conduzisse ao ensino de uma Ortodontia corretiva coerente com os anseios da Odontologia e da comunidade daquela época.

Amadureceram então seus propósitos de um aprendizado de escol, de preferência no exterior. Para tanto foram realizadas diversas diligências para atingirem esse desiderato, com diversos candidatos para bolsas, tais como Kellog Foundation e outras. Graças ao empenho do Dr. Dantas junto ao Dr. Paulino Guimarães, Presidente da Associação Brasileira de Ensino Odontológico (ABENO), foi o Dr. Sebastião Interlandi (Fig.3) agraciado com uma bolsa de estudos pelo Ponto IV, para realizar de 1961 a 1963, um curso de mestrado em Ortodontia corretiva junto à "University of Saint Louis" no Missouri, USA.

O Dr. Müller de Araújo (Fig.4), que já lecionava na Faculdade de Odontologia da USP foi indicado pelo Dr. Dantas como Auxiliar do Prof. Antonio Koch Leme Filho, na Faculdade de Odontologia de Piracicaba. Em 1960 foi contratado como Titular da Cadeira de Orto- 
dontia daquela Faculdade, convidando como assistentes Drs. Gilberto Von Zuben, Arnold Coimbra Pfaff e Darcy Flávio Nouer, transmitindo a eles as técnicas aprendidas com o Dr. Dantas.

Em 1962, ciente também da obrigatoriedade de se aperfeiçoar para

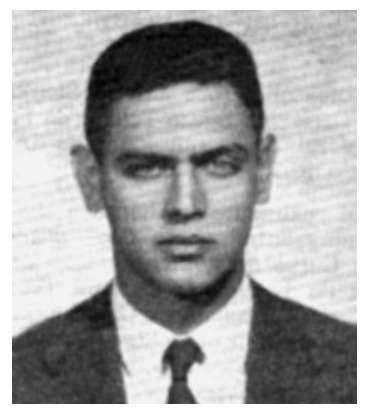

FIGURA 3 - Dr. Sebastião Interlandi, Professor de Ortodontia da Faculdade de Farmácia e Odontologia da USP.
FIGURA 4 - Dr. Manoel Carlos Müller de Araújo, Professor de Ortodontia da Faculdade de Farmácia e Odontologia de Piracicaba.

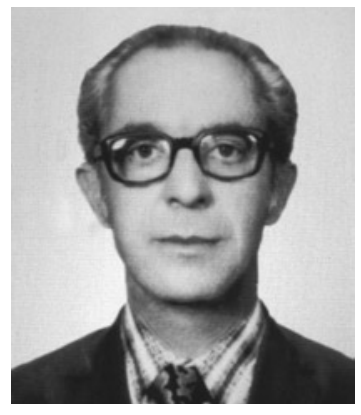

dôntico no país, reunindo colegas afeitos às lides da ciência e arte de Angle, constituindo um marco científico de relevância (Fig.5).

Foi realmente uma experiência inusitada, diria mesmo ousada para a época, porém coroada de pleno êxito, pois além de seu entusiasmo característico, a Comissão Organizadora contou com a colaboração da Sociedade Paulista de Ortodontia, na pessoa do seu Presidente, Dr. Paulo Affonso de Freitas e dos Professores Drs. Gilberto Von Zuben, Darcy Flávio Nouer, Arnaldo Coimbra Pfaff e Eduardo Amaral César, assistentes do Dr. Müller na Faculdade de Piracicaba.

Participaram também na Semana, apresentando seu prestígio e respeito os professores Earl Remfroe (USA), Carlos Garcia Novales (Uruguai), Roman Santini (Argentina), Paulino Guimarães (ABENO), José Édimo Soares Martins (Rio de Janeiro), Alfredo R. Viegas (São Paulo) e outros colegas patrícios.

No $2^{\circ}$ semestre desse mesmo ano, regressa dos Estados Unidos, o Dr. Sebastião Interlandi, após 2 anos de intensos estudos de Pós- Graduação em Ortodontia, com o título de "Master of Science" pela Universidade de Saint Louis. Volta entusiasmado e com sua vocação inata para a docência, entabula conversações com o Diretor da Faculdade de Odontologia, Dr. Adamastor Corrêa para a criação de um curso "Stricto Sensu" ao nível de mestrado, em Ortodontia, como explanaremos na próxima edição. 